\title{
Minimally Invasive Discectomy and Decompression for Lumbar Spine using Tubular Retractor System: Technique, Learning Curve and Outcomes
}

\author{
Kumar VA ${ }^{1}$ Ramanadha Reddy ${ }^{1}$ Vamsi Krishna Yerramneni ${ }^{1} \quad$ Swapnil Kolpakawar ${ }^{1}$ \\ Vishwa Kumar K.S. ${ }^{1}$ Patlolla Pratyusha ${ }^{1}$ \\ ${ }^{1}$ Department of Neurosurgery, Nizam's Institute of Medical \\ Sciences, Panjagutta, Hyderabad, India \\ Address for correspondence Vamsi Krishna Yerramneni, MCh, \\ Department of Neurosurgery, Nizam's Institute of Medical Sciences, \\ Panjagutta, Hyderabad 500082, India \\ (e-mail: vamsiky.ns@gmail.com).
}

Indian J Neurosurg 2022;11:147-152

\begin{abstract}
Objective To study the indications, technical nuances, learning curve, and outcomes associated with minimally invasive tubular discectomy of spine (MITDS) and minimally invasive tubular decompression (MITD) using the tubular retractor system and compare the outcomes with open microdiscectomy and open decompression.

Materials and Methods All patients who underwent MITDS and MITD received a trial of conservative management for 6 weeks prior to surgery. Patients who had undergone open microdiscectomy and open decompression during the same period were used as controls. Operating time, intraoperative blood loss, preop and postop visual analogue scale (VAS) scores, preop and postop Oswestry disability index (ODI) scores, duration of hospital stay, complications, and need for redo surgery were analyzed.

Results Thirty-two patients who underwent MITDS and 8 patients who underwent MITD were compared with an equal number of patients who underwent open microdiscectomy and open decompression, respectively. MITDS and MITD were associated with shorter hospital stay. Short-term pain outcome was better in MITDS

Keywords

- minimally invasive tubular discectomy of spine

- minimally invasive tubular decompression

- lumbar disc disease and MITD group, although it was not statistically significant in MITD group. Functional outcome measured in terms of ODI at 6 months was not statistically significant between minimally invasive and open procedures.

Conclusion Both MITDS and MITD have a significant learning curve and have a distinct advantage of shorter hospital stay. MITDS has the distinct advantage of better short-term pain relief compared with open procedures. For MITD, comparison of short-term pain relief requires a larger sample size. To establish long-term advantages of MITDS and MITD, larger sample size and long-term follow-up are needed.
\end{abstract}

\section{Introduction}

Lumbar disc disease (LDD) and lumbar canal stenosis (LCS) are two of the most common conditions affecting the lumbar spine. Low back pain with associated radicular pain and paresthesia is a cause of significant morbidity, leading to loss of workdays and rising healthcare expenditure with its obvious implications ${ }^{1}$. Laminectomy and discectomy were done for LDD in 1934 by Mixter and Barr. ${ }^{2}$ Since then, there has been many nuances in the surgical treatment of lumbar prolapsed intervertebral disc (PIVD), more so in the past 20 years. published online

February 10, 2022
DOI https://doi.org/

10.1055/s-0041-1722825

ISSN 2277-954X.
(C)2022. Neurological Surgeons' Society of India.

This is an open access article published by Thieme under the terms of the Creative Commons Attribution-NonDerivative-NonCommercial-License, permitting copying and reproduction so long as the original work is given appropriate credit. Contents may not be used for commercial purposes, or adapted, remixed, transformed or built upon. (https://creativecommons.org/licenses/by-nc-nd/4.0/).

Thieme Medical and Scientific Publishers Pvt. Ltd. A-12, 2nd Floor, Sector 2, Noida-201301 UP, India 
Caspar $^{3}$ introduced microsurgical technique in 1977. Foley and smith performed microendoscopic discectomy in $1997 .^{3}$

The current trend is toward minimally invasive techniques $^{4}$.In minimally invasive tubular discectomy of spine (MITDS) and minimally invasive tubular decompression (MITD), smaller incision size and sparing of paraspinal muscles, including the traditional detachment of multifidus muscle from the spine, avoids surgery-related morbidity like denervation atrophy of paraspinal muscles and subsequent occurrence of chronic axial back pain..$^{5-8}$

Minimally invasive procedures commonly employed for discectomy are microscopic discectomy using tubular retractor system (MITDS), percutaneous endoscopic lumbar discectomy (PELD).The tubular retractor system could use either an endoscope or a microscope akin to microdiscectomy. In cases of lumbar canal stenosis, "over the top" decompression (MITD) of the contralateral side can be performed by certain subtle technical modifications using the tubular retractor system. ${ }^{9}$

\section{Aims and Objectives}

- To find appropriate indications and nuances in the MITDS/ MITD technique and to look at the learning curve.

- To study the outcomes associated with MITDS/MITD using tubular retractor system.

- To compare the outcomes of MITDS, MITD with open microdiscectomy (OD), and open decompression (ODR), respectively.

\section{Materials and Methods}

This is a retrospective and prospective study which includes all patients who have undergone MITDS and MITD since June 2018 in our hospital. Patients who had undergone open microdiscectomy and open decompression during the same period were used as controls. All such patients who had undergone open microdiscectomy and open decompression and who were used as controls were operated by a different surgeon who had expertise only in open technique and a comparison was made between open and minimally invasive groups on a 1:1 basis. All minimally invasive surgical (MIS) cases were done using $22 \mathrm{~mm}$ three blade tubular retractor system (Globus MARS 3V retractor system) under pentero 900 operating microscope.

\section{Patient Evaluation and Indications of Surgery}

In the absence of cauda equina syndrome, a minimum of 6 weeks of conservative management was tried before being taken up for surgery. Preoperative imaging evaluation included MRI, CT, and dynamic X-rays of the lumbar spine. Back pain and limb pain were assessed by means of visual analogue scale (VAS) and overall functional outcomes were measured using Oswestry disability index (ODI). Operating time, intraoperative blood loss, pre- and postop VAS scores, pre- and postop ODI, duration of hospital stay, complications and need for redo surgery were analyzed.

\section{Technique}

\section{Position}

Both MITDS and MITD were done by authors under general anesthesia. Patients were placed in prone position. Abdomen should be lax, so that there is good venous drainage from spine and subsequently less blood loss. All the pressure points were protected using adequate padding with extra precaution being taken to secure the eyes.

\section{Incision and Localization}

Midline is identified by palpating the spinous process and is then confirmed under C-arm guidance ( - Fig. 1A). Using a spinal needle, correct disc space is identified under $C$ arm guidance. A vertical incision of around $2.2 \mathrm{~cm}$ is marked $1.5 \mathrm{~cm}$ away from the midline centered over the desired disc space (-Fig. 1B-1, b-2). The skin incision size is based upon the diameter of the tube. Although tubes as small as 12 to $16 \mathrm{~mm}$
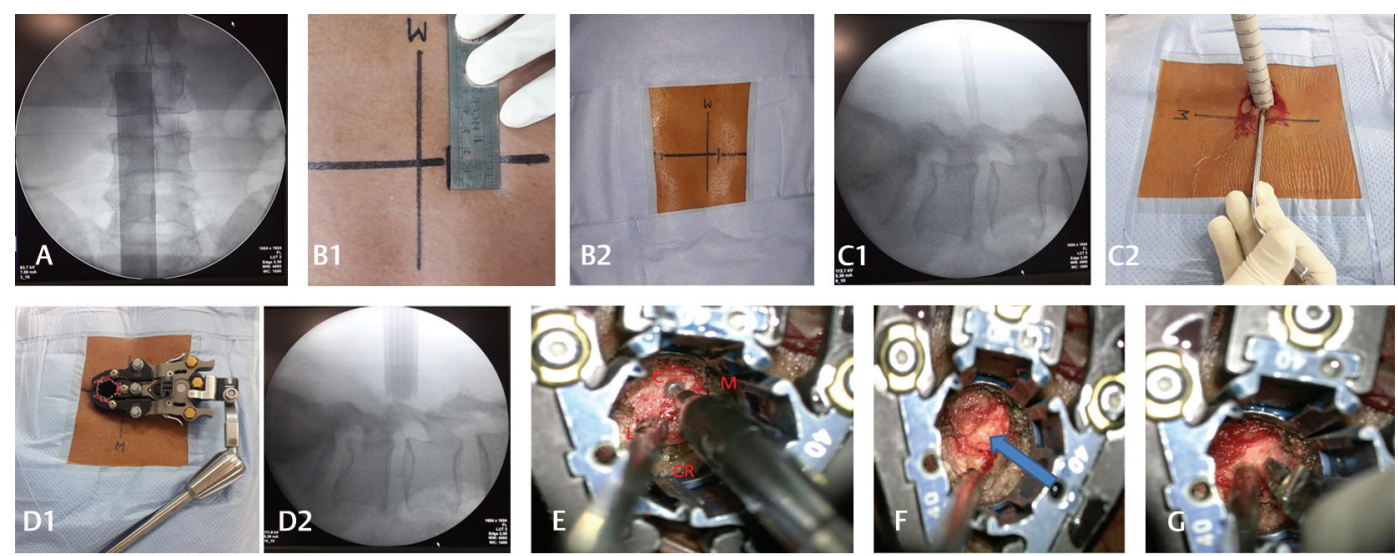

Fig. 1 (A) Marking of midline under C-arm guidance. (B1) $2.2 \mathrm{~cm}$ skin incision, $1.5 \mathrm{~cm}$ lateral to midline. (B2) Draped operative site with visible skin marking. (C1) Docking of first dilator at L4-L5 disc space under C-arm guidance. (C2) Final serial dilator with a skin marking at the length of $45 \mathrm{~mm}$. (D1) $22 \mathrm{~mm}, 3$ blade tubular retractor system connected to a flexible arm. (D2) Position of retractor system confirmed under C-arm guidance. (E) Drilling of lamina. M-medial, L-lateral, CR-cranial, C-caudal. (F) Blue arrow shows exposed ligamentum flavum. (G) Incision over disc bulge using 15 no blade. 
can be used, they require in addition bayonetted and smaller diameter Kerrison punches and other instruments. The smallest diameter tube available at the authors' institution is $22 \mathrm{~mm}$. For discectomy, the incision is on the same side as the disc prolapse, while for decompression, the incision is contralateral to the side of severe stenosis. Skin incision is deepened up to the dorsolumbar fascia, and then by blunt dissection using index finger, paraspinal muscles are swiped off the lamina and spinous process.

\section{Docking}

The smallest of the serial dilator is passed through the plane created by blunt dissection. Docking of the dilator is done at the spinolaminar junction ( - Fig. 1C-1, C-2). Serial dilators are passed over the first dilator. After passing the fourth dilator, the marking on the dilator at the level of the skin is noted to choose the appropriate blade length for the retractor system. The muscle over the lamina is scraped in all directions before passing the retractor system over the dilators. The tubular retractor is docked, so that the lower one-third of the upper lamina, the interlaminar space, and the spinolaminar junction are in the field of tubular retractor. The placement of the retractor over the correct disc space and the trajectory of the retractor system is confirmed under C-arm guidance (-Fig. 1D-1, D-2). The retractor system is then connected to a flexible arm attached to the bed rail, while the retractor is pushed down to prevent the soft tissue from coming into the field of vision. Then, under the operating microscope, soft tissue is cleared with monopolar cautery.

\section{Laminotomy and Discectomy}

Laminotomy of the superior lamina is done using a high-speed drill (3 mm cutting drill bit Medtronics drill) (-Fig. 1E). The extent of laminar drilling depends on the position of the disc bulge or extruded fragment. In cases of the disc bulge with no caudal migration, $3 \mathrm{~mm}$ of the drilling of the lower lamina is done along with ligamentum flavum removal ( - Fig. 1F). In case of caudal migration, upper part of lower lamina drilling is required to achieve complete removal of the disc fragment. Medial extent of laminotomy is the spinolaminar junction in cases of central disc herniations, while paracentral disc removal sometimes requires drilling of the medial onethird of the facet joint, and if there is associated foraminal stenosis, facet joint can be drilled further (less than 50\%). Excessive removal of facet joint can result in iatrogenic instability; hence, it should be avoided. Bone can also be removed using 90 degree or 45 degree Kerrison ronguers, starting with smaller-sized $(1 \mathrm{~mm})$ ronguers and subsequently progressing to larger-sized ones ( $2 \mathrm{~mm}, 3 \mathrm{~mm}$ ). Transverse incision is made in the ligamentum flavum with a 11 no blade till epidural fat is seen. Excision of the ligamentum flavum is generally done using 45 degree Kerrison ronguers with 1 or 2-mm foot plate. Nerve root is retracted medially, using nerve root retractor or the suction canula, and disc bulge is identified.

Annulus overlying the disc bulge is incised using No. 15 scalpel (-Fig. 1G), and disc material is removed using curved and straight punch forceps.

\section{Laminotomy in MITD}

Laminotomy of the superior lamina is done up to the ligamentum flavum attachment. Medial extent of laminotomy is the spinolaminar junction. Once the spinolaminar junction is reached, the tubular retractor is turned medially by around 30 degree (wanding), and the operating table is slightly tilted toward the contralateral side of the surgeon. This is the most important maneuver for visualizing the base of spinous process and opposite lamina. Undercutting of the base of spinous process and opposite lamina is done using high-speed drill ( - Fig. 2A, B). Ligamentum flavum should be preserved until laminotomy is complete to avoid injury to underlying dura. Enlargement of the foramina of the opposite side requires drilling of the undersurface of the superior facet.

\section{Ligmentum Flavum and Facet Excision in MITD}

After laminotomy is adequately achieved, ligamentum flavum is excised to visualize thecal sac, opposite traversing root and the opposite pedicle ( $\boldsymbol{- F i g}$. 2C). Adequate decompression is achieved if the medial border of the inferior pedicle can be felt with a ball-tip probe. If adequate decompression has not been achieved, then medial portion of the facet joint is removed, taking care not to disrupt more than 50 percent of the facet to avoid instability. In case of bilateral stenosis, decompression (laminectomy and decompression) is performed on the ipsilateral side, that is, on the side of incision followed by opposite side decompression.
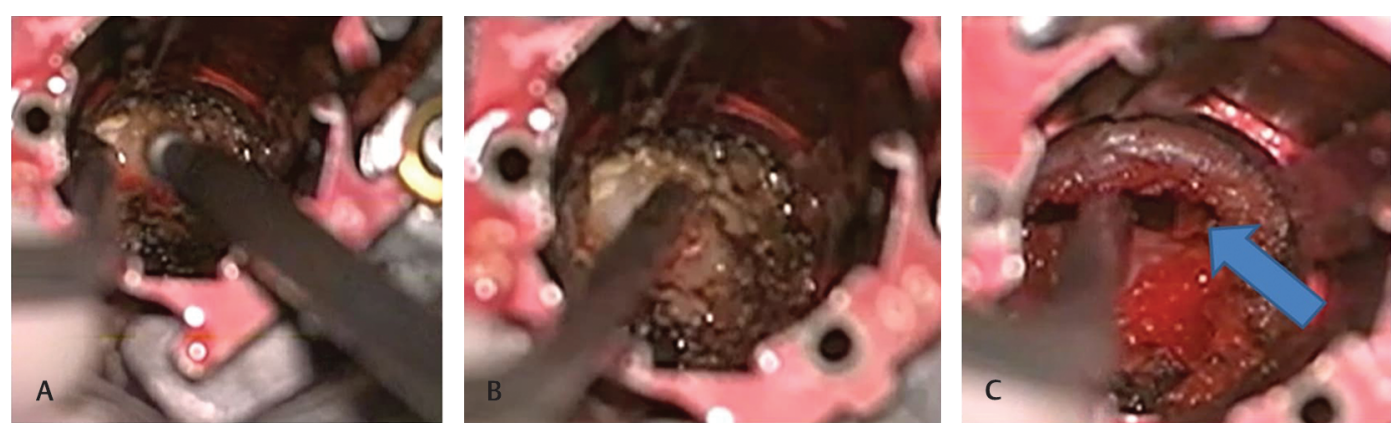

Fig. 2 (A) Undercutting of opposite lamina using high-speed drill in "over the top" minimally invasive surgical (MIS) decompression. (B) Tip of suction cannula points to the opposite lamina which has been "undercut." (C) Complete decompression after undercutting of opposite lamina and excision of ligamentum flavum. Blue arrow shows the traversing nerve root. 


\section{Closure}

After ensuring hemostasis, retractor system is slowly removed under vision. The paraspinal muscles spontaneously appose as the retractor is removed. Dorsolumbar fascia is closed using vicryl. Dermis is closed by interrupted inverting sutures using vicryl, and skin is closed using staplers or more recently with cyanoacrylate glue.

\section{Results}

A total of 32 patients who underwent MITDS and 8 patients who underwent MITD were compared with an equal number of patients who underwent open microdiscectomy and open decompression, respectively .

The characteristics of patients and surgical outcomes are shown in - Table 1.

Table 1 Patient characteristics and surgical outcomes

\begin{tabular}{|c|c|c|c|c|c|c|}
\hline & MITDS & OD & $p$-Value & MITD & ODR & $p$-Value \\
\hline Total cases & 32 & 32 & & 8 & 8 & \\
\hline \multicolumn{7}{|l|}{ Sex } \\
\hline Male & 11 & 17 & & 4 & 6 & \\
\hline Female & 21 & 15 & & 4 & 2 & \\
\hline Age (in years) & $42.32 \pm 10.96$ & $42.63 \pm 12.56$ & & $55.37 \pm 14.75$ & $56 \pm 11.04$ & \\
\hline Duration of symptoms (in months) & $9.43 \pm 10.34$ & $7.96 \pm 6.36$ & & $9.87 \pm 6.85$ & $25.75 \pm 17.36$ & \\
\hline Characteristics of symptoms & 19 & 10 & & 6 & 8 & \\
\hline Back pain with radiating pain & 11 & 17 & & 3 & 4 & \\
\hline Pain with paresthesia & 1 & 2 & & 1 & None & \\
\hline Only paresthesia & None & 2 & & 5 & 4 & \\
\hline Neurogenic claudication & 1 & 2 & & None & None & \\
\hline \multicolumn{7}{|l|}{ Foot weakness } \\
\hline \multicolumn{7}{|l|}{ Level of disc } \\
\hline $\mathrm{L} 2-3$ & 2 & 2 & & None & None & \\
\hline L3-4 & 2 & 5 & & None & 1 & \\
\hline L4-5 & 10 & 15 & & 7 & 5 & \\
\hline L5-S1 & 18 & 8 & & 1 & 2 & \\
\hline Duration of surgery (in mins) & $97.18 \pm 18.26$ & $72.66 \pm 25.12$ & 0.072 & $115 \pm 18.51$ & $77.50 \pm 16.32$ & 0.001 \\
\hline Hospital stay (in days) & $1.34 \pm 1.24$ & $2.77 \pm 0.98$ & 0.001 & $1.125 \pm 0.33$ & $3.62 \pm 1.65$ & 0.002 \\
\hline Intraop blood loss (in mL) & $97.45 \pm 21.39$ & $110.55 \pm 25.37$ & 0.379 & $139.75 \pm 52.18$ & $150 \pm 47.14$ & 0.693 \\
\hline \multicolumn{7}{|l|}{ VAS score (mean value) } \\
\hline \multicolumn{7}{|l|}{ Preoperative } \\
\hline Leg & $7.34 \pm 1.61$ & $7.8 \pm 1.65$ & & $7.37 \pm 1.85$ & $8.25 \pm 0.62$ & \\
\hline Back & $7.09 \pm 1.17$ & $7.47 \pm 1.23$ & & $7.50 \pm 1.06$ & $7.75 \pm 0.96$ & \\
\hline \multicolumn{7}{|l|}{ Postoperative } \\
\hline Leg & $2.96 \pm 0.96$ & $3.97 \pm 1.12$ & 0.561 & $3.75 \pm 1.03$ & $4.87 \pm 0.78$ & 0.753 \\
\hline Back & $3.25 \pm 1.21$ & $4.06 \pm 1.06$ & 0.224 & $3.75 \pm 1.48$ & $4.92 \pm 0.85$ & 0.615 \\
\hline \multicolumn{7}{|l|}{ 3-month follow-up- } \\
\hline Leg & $2.25 \pm 0.91$ & $3.54 \pm 1.16$ & 0.009 & $3.12 \pm 1.12$ & $3.37 \pm 0.85$ & 0.504 \\
\hline Back & $2.87 \pm 1.26$ & $3.9 \pm 0.98$ & 0.02 & $3.37 \pm 1.06$ & $3.95 \pm 0.96$ & 0.940 \\
\hline \multicolumn{7}{|l|}{ 6-month follow-up- } \\
\hline Leg & $2.00 \pm 0.91$ & $2.67 \pm 0.94$ & 0.004 & $2.25 \pm 0.88$ & $3.23 \pm 1.16$ & 0.478 \\
\hline Back & $2.75 \pm 1.31$ & $2.97 \pm 1.23$ & 0.047 & $3.12 \pm 1.12$ & $3.37 \pm 1.21$ & 0.881 \\
\hline \multicolumn{7}{|l|}{ ODI score } \\
\hline Preoperative & $68.19 \pm 8.81$ & $63.74 \pm 5.79$ & \multirow[t]{2}{*}{0.736} & $69.50 \pm 4.37$ & $67.35 \pm 3.27$ & \multirow[t]{2}{*}{0.364} \\
\hline 6-month follow-up & $32.31 \pm 14.29$ & $33.45 \pm 13.46$ & & $32.50 \pm 13.47$ & $36.25 \pm 9.07$ & \\
\hline
\end{tabular}

Abbreviations: MITD, minimally invasive tubular decompression; MITDS, minimally invasive tubular discectomy of spine; ODI, Oswestry disability index; OD, open microdiscectomy; ODR, open decompression. 


\section{Complications}

Two patients required reexploration in the immediate postoperative period for remnant disc. One patient developed severe radiculopathy, and the other had knee extension weakness and aggravated back and radicular pain after mobilization along with bladder retention.

In both the cases, residual disc was found at the same level on postoperative MRI of lumbosacral spine. In both cases, residual disc was central in location. The aforesaid complications occurred in the initial part of the learning curve.

There were four cases of intraoperative dural tear, but there was no postoperative cerebrospinal fluid (CSF) leak.

There were no intraoperative complications in the MITD, open microdiscectomy, and open decompression groups.

\section{Operating Time with Experience}

The duration of surgery came down gradually with experience. From July 2018 till June 2019, the average duration of surgery was 102 minutes. From July 2019 onward, the average duration of surgery was 96.92 minutes (-Fig. 3).

\section{Discussion}

MIS procedure for discectomy and decompression are emerging as the standard procedures.

\section{MIS Versus Open Discectomy and Decompression}

MITDS and MITD are associated with less intraoperative blood loss, less postoperative pain, shorter hospital stay, early return to work, and lower hospital charges compared with open discectomy. ${ }^{10-19}$ Level I evidence supports lower analgesic usage in patients who undergo MITDS and MITD compared with open procedures. ${ }^{18,20-22}$ However, there is conflicting data regarding operation time. ${ }^{18,20,23}$

In this study, MIS technique had longer operating time as compared with open methods which can be attributed to the learning curve as well as certain technical modifications like preservation of ligamentum flavum till the end of bone drilling. However, MIS procedures had less intraoperative blood loss and less postoperative pain, although not statistically significant. Hospital stay was much less in MIS technique, which was statistically significant, with all patients mobilized on the day of surgery and discharged on the first

Duration of surgery

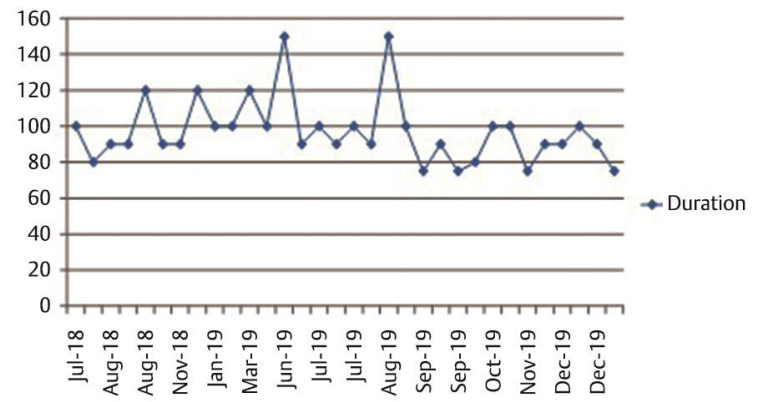

Fig. 3 Graph 1 depicting the duration of surgery over a period of 18 months. postoperative day. Pain outcome at 3 months and 6 months in terms of VAS score was better in MIS technique, which was statistically significant in case of MITDS, but was insignificant in case of MITD, which can be attributed to a small sample size. Functional outcome as measured by ODI score at 6 months was not statistically significant between the MIS and open techniques.

Although in this study there were no major complications in MIS and open groups, several studies have shown that MITDS has lower rates of surgical site infection, discitis and postoperative CSF leaks as compared with standard open discectomy. ${ }^{24,25}$ Postoperative complication rates for MITD vary between 5 to $16 \%$, with the most frequent complication being incidental durotomy. ${ }^{18,20,23}$ Preserving ligamentum flavum till the end of drilling of bone is key to avoid intraoperative complications like dural tear, nerve root injury, and CSF leak during MITDS as well as MITD. ${ }^{26}$

Although MITDS and MITD have several advantages over open discectomy and decompression as mentioned earlier, there is no difference in long-term functional outcomes, safety profile, and recurrence rates between MITDS, MITD, open discectomy and decompression, respectively. ${ }^{12,13,15,23,27-29}$

\section{MITDS Versus PELD}

Currently, MITDS and PELD are the preferred techniques for LDD. In the presence of multiple treatment options, it is always difficult to decide as to which modality is to be used in a specific case. Liu et al in their article broadly defined the indications for each of the available surgical options for LDD. ${ }^{30}$

Although PELD causes less damage to paraspinal muscles and posterior spinal elements as compared with MITDS, it has its own set of challenges when it comes dealing with severe calcified disc, migrated disc, large osteophyte, and foraminal stenosis. ${ }^{30-33}$ However, MITDS is a good modality to offer in cases of LDD associated with foraminal stenosis, partially calcified disc, and in cases of obesity. With regard to PELD, MITDS has advantage of three-dimensional view and surgeon familiarity due to the use of operating microscope.

Completely calcified disc are difficult to be treated by MITDS as well as PELD, with authors preferring open discectomy and in some cases facetectomy and fusion.

MITDS and MITD have a steep learning curve, and it takes a considerable time before a surgeon gains expertise over both these procedures.

\section{Conclusion}

Both minimally invasive tubular discectomy and decompression have a significant learning curve and have a distinct advantage of shorter hospital stay. Minimally invasive tubular discectomy has the distinct advantage of better short-term pain relief compared with open procedures. For MITD, comparison of short-term pain relief requires a larger sample size. To establish long-term advantages of MITDS and MITD, a larger sample size and long-term follow-up is needed. 


\section{Conflict of Interest}

None declared.

\section{References}

1 Holbrook TL, Grozier K, Kelsey JL, et al. The Frequency of Occurrence, Impact, and Cost of Selected Musculoskeletal Conditions in the United States. Chicago: American Academy of Orthopedic Surgeons; 1984 154-156

2 Mixter WJ, Barr JS. Rupture of the intervertebral disc with involvement of the spinal canal. NEnglJMed 1934;211:210-215

3 Caspar W. A new surgical procedure for lumbar disc herniation causing less tissue damage through a microsurgical approach. Adv Neurosurg 1977;4:74-80

4 Gibson JN, Waddell G. Surgical interventions for lumbar disc prolapse: updated Cochrane Review. Spine 2007;32(16): $1735-1747$

5 Arts M, Brand R, van der Kallen B, Lycklama à Nijeholt G, Peul W. Does minimally invasive lumbar disc surgery result in less muscle injury than conventional surgery? A randomized controlled trial. Eur Spine J 2011;20(1):51-57

6 Adams MA, Hutton WC. The mechanical function of the lumbar apophyseal joints. Spine 1983;8(3):327-330

7 Goel VK, Fromknecht SJ, Nishiyama K, Weinstein J, Liu YK. The role of lumbar spinal elements in flexion. Spine 1985; 10(6):516-523

8 Hindle RJ, Pearcy MJ, Cross A. Mechanical function of the human lumbar interspinous and supraspinous ligaments. J Biomed Eng 1990;12(4):340-344

9 Smith ZA, Fessler RG. Paradigm changes in spine surgery: evolution of minimally invasive techniques. Nat Rev Neurol 2012;8(8):443-450

10 Arts MP, Brand R, van den Akker ME, et al. Tubular diskectomy vs conventional microdiskectomy for the treatment of lumbar disk herniation: 2-year results of a double-blind randomized controlled trial. Neurosurgery 2011;69(1):135-144, discussion 144

11 Garg B, Nagraja UB, Jayaswal A. Microendoscopic versus open discectomy for lumbar disc herniation: a prospective randomised study. J Orthop Surg (Hong Kong) 2011;19(1):30-34

12 Palmer S. Use of a tubular retractor system in microscopic lumbar discectomy: 1 year prospective results in 135 patients. Neurosurg Focus 2002;13(2):E5

13 Mobbs RJ, Li J, Sivabalan P, Raley D, Rao PJ. Outcomes after decompressive laminectomy for lumbar spinal stenosis: comparison between minimally invasive unilateral laminectomy for bilateral decompression and open laminectomy: clinical article. J Neurosurg Spine 2014;21(2):179-186

14 Cho DY, Lin HL, Lee WY, Lee HC. Split-spinous process laminotomy and discectomy for degenerative lumbar spinal stenosis: a preliminary report. J Neurosurg Spine 2007;6(3): 229-239

15 Righesso O, Falavigna A, Avanzi O. Comparison of open discectomy with microendoscopic discectomy in lumbar disc herniations: results of a randomized controlled trial. Neurosurgery 2007;61(3):545-549, discussion 549

16 Cahill KS, Levi AD, Cummock MD, Liao W, Wang MY. A comparison of acute hospital charges after tubular versus open microdiskectomy. World Neurosurg 2013;80(1-2):208-212

17 Palmer S, Turner R, Palmer R. Bilateral decompression of lumbar spinal stenosis involving a unilateral approach with microscope and tubular retractor system. J Neurosurg 2002; 97(2, Suppl):213-217
18 Rahman M, Summers LE, Richter B, Mimran RI, Jacob RP. Comparison of techniques for decompressive lumbar laminectomy: the minimally invasive versus the "classic" open approach. Minim Invasive Neurosurg 2008;51(2):100-105

19 Khoo LT, Fessler RG. Microendoscopic decompressive laminotomy for the treatment of lumbar stenosis. Neurosurgery 2002;51(5, Suppl):S146-S154

20 Lee C-W, Yoon KJ, Ha SS. Comparative analysis between three different lumbar decompression techniques (microscopic, tubular, and endoscopic) in lumbar canal and lateral recess stenosis: preliminary report. BioMed Res Int 2019;2019:6078469

21 Brock M, Kunkel P, Papavero L. Lumbar microdiscectomy: subperiosteal versus transmuscular approach and influence on the early postoperative analgesic consumption. Eur Spine J 2008;17(4):518-522

22 German JW, Adamo MA, Hoppenot RG, Blossom JH, Nagle HA. Perioperative results following lumbar discectomy: comparison of minimally invasive discectomy and standard microdiscectomy. Neurosurg Focus 2008;25(2):E20

23 Castro-Menéndez M, Bravo-RicoyJA, Casal-Moro R, HernándezBlanco M, Jorge-Barreiro FJ. Midterm outcome after microendoscopic decompressive laminotomy for lumbar spinal stenosis: 4-year prospective study. Neurosurgery 2009;65(1): 100-110, discussion 110, quiz A12

24 Caspar W, Campbell B, Barbier DD, Kretschmmer R, Gotfried Y. The Caspar microsurgical discectomy and comparison with a conventional standard lumbar disc procedure. Neurosurgery 1991;28(1):78-86, discussion 86-87

25 Ebeling U, Reichenberg W, Reulen HJ. Results of microsurgical lumbar discectomy. Review on 485 patients. Acta Neurochir (Wien) 1986;81(1-2):45-52

26 Clark AJ, Safaee MM, Khan NR, Brown MT, Foley KT. Tubular microdiscectomy: techniques, complication avoidance, and review of the literature. Neurosurg Focus 2017;43(2):E7

27 Huang TJ, Hsu RW, Li YY, Cheng CC. Less systemic cytokine response in patients following microendoscopic versus open lumbar discectomy. J Orthop Res 2005;23(2):406-411

28 Teli M, Lovi A, Brayda-Bruno M, et al. Higher risk of dural tears and recurrent herniation with lumbar micro-endoscopic discectomy. Eur Spine J 2010;19(3):443-450

29 Arts MP, Brand R, van den Akker ME, Koes BW, Bartels RH, Peul WC; Leiden-The Hague Spine Intervention Prognostic Study Group (SIPS). Tubular diskectomy vs conventional microdiskectomy for sciatica: a randomized controlled trial. JAMA 2009;302(2):149-158

30 Liu X, Yuan S, Tian Y, et al. Comparison of percutaneous endoscopic transforaminal discectomy, microendoscopic discectomy, and microdiscectomy for symptomatic lumbar disc herniation: minimum 2-year follow-up results. J Neurosurg Spine 2018;28(3):317-325

31 Chen Z, Zhang L, Dong J, et al. Percutaneous transforaminal endoscopic discectomy versus microendoscopic discectomy for lumbar disc herniation: two-year results of a randomized controlled trial. Spine 2020;45(8):493-503

32 Yokosuka J, Oshima Y, Kaneko T, Takano Y, Inanami H, Koga $\mathrm{H}$. Advantages and disadvantages of posterolateral approach for percutaneous endoscopic lumbar discectomy. J Spine Surg 2016;2(3):158-166

33 Gushcha A, et al. Advantages and weaknesses of percutaneous endoscopic lumbar discectomy: algorithm selection. Coluna/ Columna 2018;17(3):200-205 